\title{
Deep brain stimulation of the dorsal anterior cingulate cortex for the treatment of chronic neuropathic pain
}

\author{
Jennifer F. Russo, BFA, ${ }^{1,2}$ and Sameer A. Sheth, MD, PhD² \\ ${ }^{1}$ Columbia University College of Physicians and Surgeons and 2Department of Neurological Surgery, Columbia University \\ Medical Center, New York, New York
}

\begin{abstract}
Chronic neuropathic pain is estimated to affect $3 \%-4.5 \%$ of the worldwide population. It is associated with significant loss of productive time, withdrawal from the workforce, development of mood disorders such as depression and anxiety, and disruption of family and social life. Current medical therapeutics often fail to adequately treat chronic neuropathic pain. Deep brain stimulation (DBS) targeting subcortical structures such as the periaqueductal gray, the ventral posterior lateral and medial thalamic nuclei, and the internal capsule has been investigated for the relief of refractory neuropathic pain over the past 3 decades. Recent work has identified the dorsal anterior cingulate cortex (dACC) as a new potential neuromodulation target given its central role in cognitive and affective processing. In this review, the authors briefly discuss the history of DBS for chronic neuropathic pain in the United States and present evidence supporting dACC DBS for this indication. They review existent literature on dACC DBS and summarize important findings from imaging and neurophysiological studies supporting a central role for the dACC in the processing of chronic neuropathic pain. The available neurophysiological and empirical clinical evidence suggests that dACC DBS is a viable therapeutic option for the treatment of chronic neuropathic pain and warrants further investigation.
\end{abstract}

http://thejns.org/doi/abs/10.3171/2015.3.FOCUS1543

KEY WORDS deep brain stimulation; anterior cingulate cortex; chronic pain; neuropathic pain; ACC; dACC

$\mathrm{C}$ HRONIC pain affects approximately 100 million American adults each year and results in an annual incremental health care cost of $\$ 560-\$ 635$ billion. ${ }^{66}$ The economic burden of chronic pain is multiplied when loss of productive work time is considered. ${ }^{143}$ Chronic pain has been associated with impairment in cognition and attention, ${ }^{78}$ development of psychiatric comorbidities such as depression and anxiety, ${ }^{48}$ dependence on opioid analgesia, and decline in social functioning. ${ }^{59}$ Further, many chronic pain states, such as neuropathic pain, remain difficult if not impossible to treat with available therapeutics. ${ }^{159}$ For these reasons, the impact of chronic pain on public well-being cannot be overstated.

Neuropathic pain is defined by the International Association for the Study of Pain (IASP) as "pain arising as a direct consequence of a lesion or disease affecting the somatosensory system.." ${ }^{\prime 8}$ When neuropathic pain extends beyond the period of injury and healing, it becomes chronic disease. ${ }^{45,70,74}$ The development of chronic neuropathic pain is associated with alterations in function of the peripheral, spinal, and central pain pathways, which result in abnormal activity, leading to the development of allodynia, the experience of nonnociceptive stimuli as painful; hyperalgesia, an abnormally increased pain response to nociceptive stimuli; and spontaneous pain, which can be constant and debilitating. 5,24,40,43,53,58,62 Chronic neuropathic pain arising from aberrant nervous system activity is particularly resistant to conventional medical therapies. ${ }^{18}$ Additionally, many of the medications used to treat neuropathic pain by modulating aberrant activity in the peripheral nervous system, such as carbamazepine, gabapentin, tricyclic antidepressants, serotonin- and norepinephrineselective reuptake inhibitors, are associated with significant side effects, such as sedation and nausea.$^{45}$ These treatments, which act peripherally, are unable to address pathologic changes in the central nervous system, which are implicated in the development and maintenance of chronic pain.

ABBREVIATIONS ACC = anterior cingulate cortex; $\mathrm{dACC}=$ dorsal ACC; DBS = deep brain stimulation; $\mathrm{DTI}=$ diffusion tensor imaging; fMRI = functional $\mathrm{MRI}$; $\mathrm{IASP}=\mathrm{Inter}-$ national Association for the Study of Pain; IC = internal capsule; LTP = long-term potentiation; MRS = MR spectroscopy; PAG = periaqueductal gray; PVG = periventricular gray; VAS = visual analog scale; VPL/VPM = ventral posterior lateral and medial thalamic nuclei.

SUBMITTED February 1, 2015. ACCEPTED March 23, 2015.

INCLUDE WHEN CITING DOI: 10.3171/2015.3.FOCUS1543.

DISCLOSURE The authors report no conflict of interest concerning the materials or methods used in this study or the findings specified in this paper. 
Both internationally and in the United States, the use of deep brain stimulation (DBS) has been investigated for the treatment of chronic neuropathic pain that is refractory to conventional medical therapy. ${ }^{14,21,28,30,46,60,63,79,81,115,116,137}$ Investigations into the use of DBS targeting various areas of the brain, including the periventricular gray (PVG), sensory thalamus, and the internal capsule (IC), have yielded valuable information regarding patient selection, stimulation parameters, operative technique, and outcome measurement. ${ }^{80}$ They have also served to highlight the complexity and burden associated with the management of chronic pain.

In this review, we briefly review the history of DBS for chronic pain and present evidence supporting DBS of the dorsal anterior cingulate cortex (dACC). We summarize important findings from recent neuroimaging and neurophysiology studies supporting a central role for the dACC in the development of chronic neuropathic pain and review existent literature on DBS of the dACC for this indication.

\section{DBS for Chronic Pain: Subcortical Targets}

The idea of using DBS to treat chronic pain has its origins in the development of the gate control theory of pain as described by Melzack and Wall in 1965. ${ }^{97,102}$ This theory, although now mostly supplanted by newer models such as the neuromatrix theory of pain, ${ }^{96,98-100}$ was instrumental in establishing the central nervous system as an active partner in the development of chronic pain states. Over the past 3 decades, multiple neural targets have been explored for chronic stimulation, including the periaqueductal gray (PAG) region, ${ }^{57}$ the ventral posterior lateral and medial thalamic nuclei (VPL/VPM), ${ }^{14,123}$ the IC, ${ }^{1}$ and, most recently, the dACC.

Under the US Medical Device Amendment of 1976, which compelled the US Food and Drug Administration to require DBS device manufacturers to conduct studies showing benefit of DBS for the treatment of chronic pain, 2 Medtronic-sponsored, open-label, multicenter trials were conducted. In the first of these trials, which enrolled 196 patients from 1989 to 1992 , model 3380 DBS leads were implanted into either the VPL/VPM or the PAG..$^{29}$ This trial was supplanted by a second trial in 1992, utilizing lead model 3387, which had replaced model 3380. This second trial enrolled 50 patients between 1992 and 1995. Both trials were closed early due to slow enrollment and unexpectedly low efficacy, as determined by the limited reduction in pain scores postoperatively.

The criterion for success for the model 3380 trial was defined a priori as at least half of patients with internalized devices reporting $\geq 50 \%$ pain reduction at 1 year. For the 3387 model, success was defined as at least half of the patients with internalized devices falling into 1 of 3 outcome categories at 1 year: excellent, $\geq 70 \%$ pain relief with complete cessation of narcotic drugs; good, $\geq 50 \%$ relief and no narcotic usage; moderate, $30 \%-49 \%$ pain relief and at least a 1-level decrease in analgesic usage. Any other result, including withdrawal from the study, was considered treatment failure. These values are in contrast to the $30 \%$ reduction criterion used commonly to evaluate efficacy of pharmaceutical pain relievers. For both studies, only those patients who achieved a reduction in pain of $\geq$ $50 \%$ during a test stimulation period immediately postoperatively with externalized leads went on to the next stage for full device internalization.

For the first trial, $46.1 \%$ of patients reported $\geq 50 \%$ reduction in pain at 1 year and $17.8 \%$ at 24 months, and for the second trial, $16.2 \%$ had $50 \%$ reduction at 1 year and $13.5 \%$ at 24 months. Neither study achieved the a priori criteria for success. No major reduction in narcotic medication usage was observed in either trial. Additionally, withdrawals and dropouts accounted for $70 \%-73 \%$ of patients at the 24-month outcome point, with a higher proportion of responders represented in this group. The weakness of these results led the device manufacturer to reconsider pursuit of marketing approval for the treatment of chronic pain.

A number of limitations have been identified in the design and execution of the studies described above. First, these studies consisted of a collection of prospective case series from participating centers. These series were neither randomized nor case controlled. Subjects were drawn from a heterogeneous pain population, with a large variety of syndrome types and etiologies. Interventions varied between VPL/VPM and PAG stimulation in an uncontrolled manner, and no uniform stimulation parameters were employed. Additionally, a variable number of electrodes were used per patient. Use of validated outcome measurement tools was limited to the administration of the visual analog scale (VAS) score during the 3387 trial only. All other measurements of pain reduction upon which assessment of efficacy was based were subjective and unblinded. ${ }^{113}$

As a result of these studies, DBS for chronic pain has remained "off-label" in the United States, and, as a result, very little additional formal study has been undertaken. Most of the current literature on DBS for chronic pain has come from investigators in the United Kingdom, Europe, and Canada. These more recent studies have benefited from improved imaging techniques, updated DBS device design, and procedural refinement. In addition, continued work to determine which chronic pain etiologies are most responsive to this therapeutic intervention has led to improvements in patient selection. Finally, advances in the neuroscience of pain have opened up the possibility of new neural targets, such as the dACC, which hold promise for effective pain relief for some chronic pain patients. ${ }^{67,68,71}$, $75-77,83,85,90,107,120,121,128,130,149,163-166$,

\section{The Role of the dACC in Pain Processing}

An extensive body of literature has been devoted to understanding the role of the AACC in human cognition. The dACC has been implicated in circuits involving decision making, emotional salience, learning, reward processing, empathy, attention, intention, addiction, and the affective aspect of pain. $711,13,31,44,47,52,55,69,72,127,126,138,152-154,157$ This region has been targeted successfully with lesioning techniques for the treatment of affective disorders, ${ }^{9,141}$ obsessive-compulsive disorder, ${ }^{136}$ and chronic refractory pain, ${ }^{152}$ highlighting the diversity of neurological processes with which it is involved. Modern imaging techniques have demonstrated the extensive functional and anatomical con- 
nections traveling to, from, and through this region, which underlie these diverse processes. ${ }^{3,8,93,103,108,109,117,118,131,137,150}$

In 1962, Foltz and White published their seminal paper, "Pain 'Relief' by Frontal Cingulumotomy," which ignited interest in discovering the role of cingulotomy in the treatment of chronic refractory pain. ${ }^{51}$ Drawing on lessons from early psychiatric neurosurgery, and particularly on observations made of the effect of lobotomy on pain perception and autonomic function, Foltz and White hypothesized that transection of the cingulum bundle might benefit those patients with a disproportionally large affective component to their pain. In the discussion of their findings, they reported a universal decrease in the distress associated with chronic pain.

The initial results regarding the use of cingulotomy for the treatment of refractory pain described above were replicated and expanded by numerous investigators, including Ballantine and Hurt at the Massachusetts General Hospital in Boston, who introduced a stereotactic approach in 1966..$^{9,25,162}$ Stereotactic cingulotomy, which allows for more precise targeting, continues to be in use today for the treatment of malignant and nonmalignant chronic pain. Although slight variations have been reported, the target is commonly described as being located $7 \mathrm{~mm}$ from the midline, $20 \mathrm{~mm}$ posterior to the anterior tip of the frontal horns of the lateral ventricle, and $1 \mathrm{~mm}$ above the roof of the ventricles, bilaterally. ${ }^{140}$ This region corresponds to Brodmann areas 24 and 32 and has been variably called either the dACC or the dorsal anterior midcingulate cortex (daMCC) in the literature.

The empirical work identifying the dACC as a target for treatment of chronic pain is supported by more recent imaging and neurophysiological evidence describing the role of the anterior cingulate in the perception of pain. The development of imaging modalities such as diffusion tensor imaging (DTI), functional MRI (fMRI), positron emission tomography, and voxel-based morphometry has allowed investigators to better characterize the structure and function predicted by these early studies, confirming the central role of the dACC in the perception of chronic pain, and allowing an increasingly nuanced therapeutic approach. ${ }^{8}$ Studies using fMRI have consistently demonstrated increased activation of the dACC during both empathic and experienced pain, ${ }^{111}$ supporting a hypothesis that the dACC is implicated in the affective component of pain.

\section{Neuroimaging of Chronic Pain}

Melzack, having already introduced the concept of a neuromatrix, formulated his understanding of pain processing in the following way: "The anatomical substrate of the body-self, I propose, is a large, widespread network of neurons that consists of loops between the thalamus and cortex as well as between the cortex and limbic system. I have labeled the entire network, whose spatial distribution and synaptic links are initially determined genetically and later are sculpted by sensory inputs, as a neuromatrix."99

The earliest neuroimaging studies of pain looked primarily at acute pain in healthy controls..$^{10,35,38,91,122,158}$ In 2000, Peyron and colleagues undertook a thorough metaanalysis of the pain neuroimaging studies published be- tween 1991 and 1999. The meta-analysis revealed a consistent pattern of activation in a diverse array of brain regions in response to acute pain. Most reliably, hemodynamic changes were observed in the bilateral insula, primary and secondary somatosensory regions, and the dACC, corresponding primarily to Brodmann area $24 .{ }^{117}$ These findings suggest that the experience of pain is a multimodal event, representing the output of a series of complex interactions between emotional processing, memory, cognitive, and sensory centers constituting a "pain neuromatrix."101 (Fig. 1).

More recent work has focused on understanding the

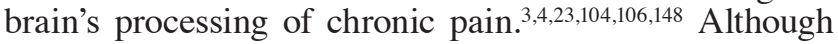
execution and analysis of chronic pain imaging is complicated by heterogeneity of the clinical entities under study and inability to control experimental features, evidence for unique yet overlapping neurosignatures of various chronic pain disorders is amassing. A recent review by Apkarian discussed the findings of neuroimaging studies devoted to elucidating chronic pain states published over the past decade. ${ }^{4} \mathrm{He}$ found that not only did each chronic pain syndrome evoke a unique pattern of activity but also that chronic pain generally activates brain regions that are more involved with emotional and motivational states than with acute nociception, such as the dACC.

The altered activity in chronic pain patients described above is complemented by changes in gray and white matter. Decreased gray matter density in areas involved in nociception has been reported in multiple chronic pain conditions. ${ }^{3,95}$ Mordasini and colleagues used voxel-based morphometry to investigate gray matter changes in 20 men with refractory chronic pelvic pain syndrome and 20 healthy age-matched controls. They identified a significant reduction in gray matter volume in the anterior cingulate cortex (ACC). Further, the reduction in gray matter volume in the ACC correlated with measures of bother or unpleasantness associated with the pain. ${ }^{105}$ An additional study by Rodriguez-Raecke and colleagues monitored changes in brain morphometry in 20 patients with chronic pain due to hip osteoarthritis who underwent hip replacement. ${ }^{125}$ When compared with controls preoperatively, patients with chronic pain were shown to have significantly less gray matter in the ACC, the insular cortex and operculum, the orbitofrontal cortex, and the dorsolateral prefrontal cortex, which corresponded to duration of pain. At the postoperative time point when the patients reported being pain free, an increase in gray matter was observed in the same area, suggesting that these changes may be at least partially reversible with appropriate analgesia. This observation suggests that changes in morphometry likely reflect long-term neuroplastic changes rather than neuronal loss. It also suggests that these changes are likely to have resulted from chronic pain and/or its functional and emotional consequences, rather than having predisposed the patient to the development of pathologic pain. The development and maintenance of neuroplastic changes in chronic pain is an area of active research and is discussed briefly below. ${ }^{95}$

An additional body of literature has been devoted to exploring the utilization of advanced neuroimaging techniques to understand the specific contribution of the ACC to the experience of pain. Classically, the ACC has been 


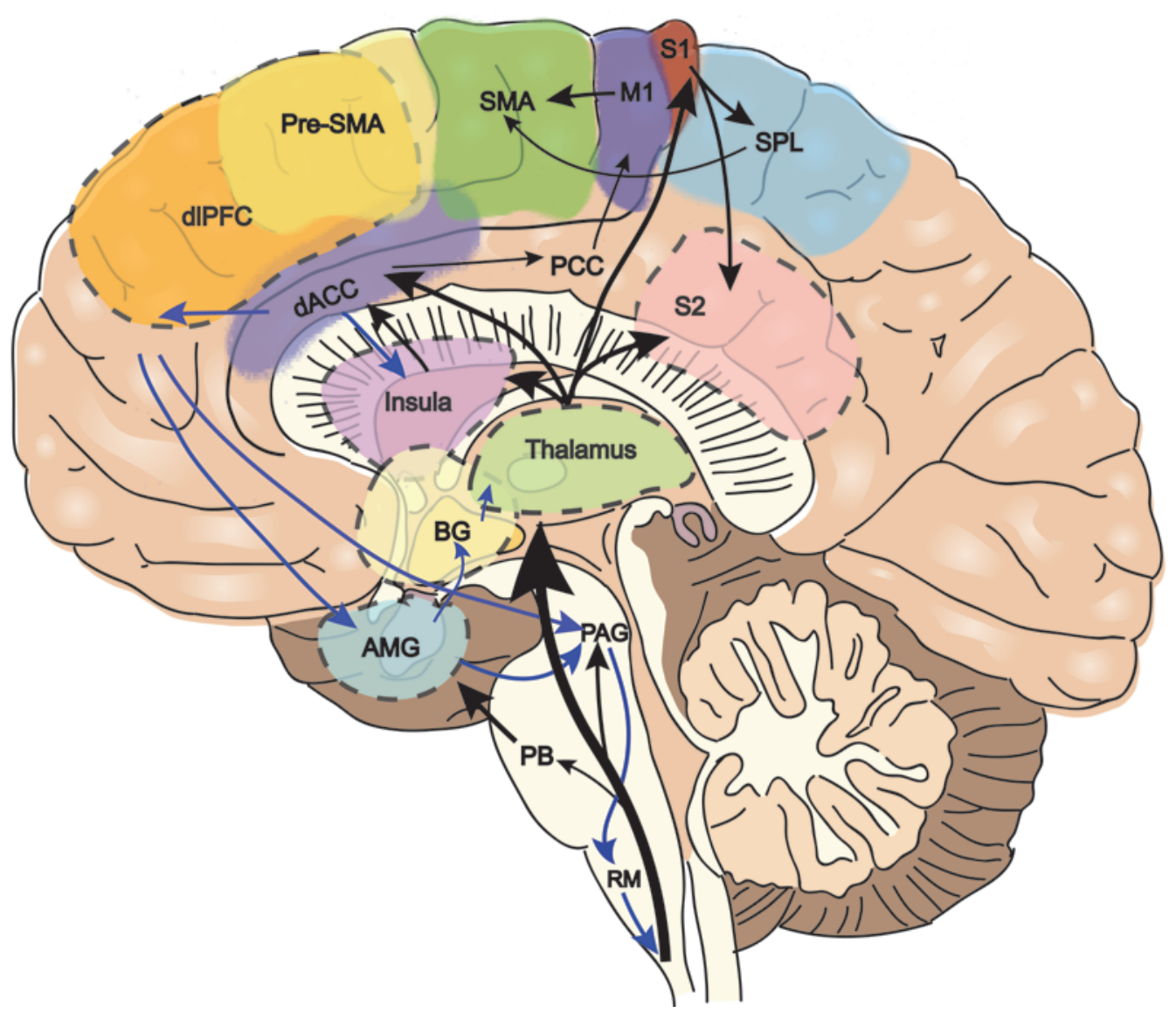

FIG. 1. Illustration based on the neuroimaging studies that suggest the experience of pain involves complex interaction between brain regions involved in emotional processing, memory, cognition, sensation, and motor planning. Ascending pain pathways are shown with black arrows. The classically described pathway (lateral spinothalamic tract, thalamus, primary sensory cortex) is one of these ascending pathways. Blue arrows represent descending modulatory pain pathways. Both the ascending and descending pathways involve regions of the brain involved in not just primary sensation but also emotional and cognitive processing. These associated regions include the dACC, dorsolateral prefrontal cortex (dIPFC), and amygdala (AMG). Labeled regions out of (lateral to) the midsagittal section are outlined with dashed lines. $B G=$ basal ganglia; $M 1=$ primary motor cortex; $P B=$ parabrachial nuclei; $\mathrm{PCC}=$ posterior cingulate cortex; RM = rostral medulla; $\mathrm{S} 1$ = primary somatosensory cortex; $\mathrm{S} 2$ = secondary somatosensory cortex; SMA = supplementary motor area; SPL = superior parietal lobule.

described as consisting of 2 major subdivisions with distinct functions: the dorsal cognitive and the rostral-ventral affective divisions. ${ }^{154}$ The cognitive division, which has abundant interconnections to and from the lateral prefrontal cortex, parietal cortex, and supplementary motor areas, has been ascribed a number of executive and evaluative functions, such as error processing, working memory, and anticipation..$^{22}$ The affective subdivision, which includes rostral areas 24, 33, and 25, has significant connections to the amygdala and PAG and is thought to be involved in salience determination and emotional learning. ${ }^{44} \mathrm{Al}-$ though this view of functionally distinct subdivisions of the ACC has largely been replaced by more nuanced models, ${ }^{6,50,133,152,153}$ it continues to impact our understanding of the role of the $\mathrm{dACC}$ in the experience of pain.

Most commonly, the dACC is described as mediating the unpleasant or affective aspect of pain rather than the sensory-discriminative characteristics. This description is supported by a breadth of imaging studies that have shown that the dACC is activated during empathic pain as well as by the direct experience of pain..$^{12,35,49,111,122,139}$ Several thorough reviews have been published recently that discuss the neuroimaging evidence for the intersection of perceived and experienced pain in the dACC..$^{84,132}$ This topic will not be covered extensively here, but evidence supports the view that the ACC is primarily involved in the motivational-affective evaluation of pain rather than in the detection of stimulus characteristics.

Despite major advancements in neuroimaging techniques, several important limitations should be noted in the imaging of chronic pain. First, the study of chronic pain is complicated by heterogeneity in pain location, inciting injury, duration of pain, and level of spontaneous pain. ${ }^{82}$ Samples are often small, and appropriate controls may be difficult to find. Additionally, it is often impossible and unethical to restrict the use of analgesia medication in chronic pain patients. The effect of these medications on imaging has not been fully determined. Further, individual differences in the anatomy of the cingulate cortex complicate group analysis and can make localization difficult. ${ }^{42,54}$ Finally, the cortical regions identified in pain contain mixed populations of neurons with different response 
characteristics and firing properties. Changes in blood flow do not distinguish between activation of excitatory and inhibitory neurons, and limitations on voxel size mean that each image unit contains hundreds to thousands of neurons. ${ }^{37}$ Painful mechanical and/or thermal stimulation likely activates multiple types of cells in a given region; this fact cannot be captured with sufficient granularity with current imaging techniques. Direct measures of neuronal activity are needed to corroborate neuroimaging findings.

\section{Neurophysiology}

Single-neuron recordings in awake humans provide the most direct evidence of cortical function. In 1999, Hutchison and colleagues identified neurons within the human dACC that respond selectively to thermal and mechanical stimuli in 11 patients undergoing cingulotomy for treatment of psychiatric disease. ${ }^{65}$ Most of the cells identified responded selectively to 2 or 3 painful modalities but not to innocuous stimuli below the pain threshold. Additionally, in a patient, a neuron that responded to observation of painful stimuli being applied to another patient demonstrated activation during anticipation of receipt of the same stimuli. High-frequency electrical stimulation failed to elicit painful sensations. These results provide direct evidence that dACC neurons are involved in the processing of pain.

Additional information is provided by the use of magnetic resonance spectroscopy (MRS) to detect biochemical changes in the brain. MRS relies on analysis of the metabolites present in regions of the brain to detect changes associated with functional abnormalities. Siddall and colleagues used MRS to determine whether it was possible to discriminate subjects with chronic low-back pain from controls. MR spectra of the dACC, prefrontal cortex, and thalamus of 32 patients with low-back pain and 33 healthy controls were analyzed using pattern recognition techniques. The investigators found that they could reliably distinguish between subjects and controls with an accuracy of $100 \%$ using spectra obtained from dACC, $99 \%$ from the thalamus, and $97 \%$ from the prefrontal cortex. ${ }^{137}$ Comparable results were reported in an MRS study of patients with spinal cord injury, suggesting that the changes observed may be generalizable to other chronic pain conditions. ${ }^{142}$ Recent animal studies suggest that these findings may reflect neuroplastic changes in the dACC that are common to multiple chronic pain etiologies.

\section{Plasticity in the ACC}

Recent work in rodent models of neuropathic pain have focused on long-term potentiation (LTP) in the ACC as a central mechanism for initiating and maintaining pathologic pain. ${ }^{15,26,27,87,89,136,144,167}$ In a recent review summarizing the work in this area over the past decade, Zhuo describes at least 4 different forms of LTP involving both pre- and postsynaptic mechanisms, including increased presynaptic glutamate release and increased postsynaptic trafficking of the GluA1 $\alpha$-amino-3-hydroxy 5-methyl-4-isoxazole propionate (AMPA) receptors to the cell membrane in level V ACC pyramidal neurons. ${ }^{165}$ Initiation and maintenance of LTP has been shown to be dependent upon increased phosphorylation of the atypical kinase, PKM ร. $^{73,87,88,134,155}$ Inhibition of PKM $\zeta$ activity resulted in diminished spontaneous pain behaviors and decreased glutamatergic transmission, suggesting that LTP of the ACC is essential for the establishment of pathologic pain states.

The findings described above also suggest a potential mechanism of action for the therapeutic effect of dACC DBS in chronic pain. In a rodent model of cortical infarct, Cooperrider and colleagues observed evidence of cortical reorganization, increased synaptic density, and upregulation of markers of LTP following chronic electrical stimulation of the cerebellar output. ${ }^{34}$ This study suggests that chronic stimulation has the potential to interrupt the pathologic changes in the dACC responsible for maintenance of chronic neuropathic pain by modulating the expression of mediators of neuronal plasticity.

\section{Previous Studies of dACC DBS for Chronic Pain}

The first case series of electrical stimulation of the anterior cingulate was published by Lewin and Whitty in $1960 .{ }^{86}$ Based upon studies conducted in animals in which stimulation of the anterior cingulate was shown to alter autonomic function, these investigators conducted electrical stimulation of the ACC in 15 awake human subjects undergoing cingulotomy. During stimulation, patients were asked to engage in simple memory tests and calculations. Response to stimulation was monitored and recorded, although effects were sparse and inconsistent. Overall, the researchers observed only 8 positive responses to 92 bilateral stimulations. These responses consisted of momentary arrest of respiration in 3 cases of stimulation, momentary arrest of talking in 2 cases. Other responses included vomiting, regurgitating, tonic stiffening, and epigastric sensation. Overall, the researchers considered the results of their study to be largely negative and concluded, based on these results, that autonomic regulation was unlikely to be the usual function of these areas.

A second case report was published in 2007 by Spooner and colleagues, representing the first such report in which standard DBS electrodes were used to administer high-frequency electrical stimulation of the dACC to treat neuropathic pain. The patient described in this report had refractory neuropathic pain as a result of a complete spinal cord injury at the C-4 level, and had undergone numerous prior surgical and medical interventions without relief. DBS implantation of the bilateral cingulate cortex and unilateral PVG were undertaken, and a 1-week blinded stimulation period was completed prior to permanent implantation. Pain relief was assessed using the VAS and by tracking pain medication usage. Both PVG and dACC stimulation decreased VAS pain rating and led to a reduction in subcutaneous lidocaine usage. In addition, bilateral cingulate stimulation improved the patient's mood and reduced pain more completely than PVG stimulation. The investigators concluded that $\mathrm{dACC}$ stimulation does indeed target the affective component of pain, which can involve feelings of suffering, fear, anxiety, and depression. ${ }^{141}$ 
An additional case report of dACC DBS for chronic pain was published by Boccard et al..$^{16}$ in 2013 as a prequel to the publication of a larger case series. The patient described in this case had suffered brachial plexus injury as a result of a motorcycle accident. Over the course of several years, he developed additional neuropathic pain in his legs and feet that was treated with laminoplasty, but this was shortly followed by the development of a progressive full-body pain that left him clinically depressed and suicidal. The patient opted to undergo dACC DBS, with good effect. Neuropsychological assessment at 1-year postimplantation showed no significant change in test performance apart from selective improvement on the Stroop color-word interference task. Follow-up assessment did reveal an increase in self- and caregiver-rated apathy and executive dysfunction scales on the Frontal System Behavior Evaluation Scale.

Boccard and colleagues subsequently published a larger case series involving 16 patients, including the patient described above, who underwent dACC DBS. ${ }^{17}$ In this pilot series, 15 patients with refractory pain who underwent bilateral DBS implantation of the anterior cingulate were assessed postoperatively using multiple pain and quality of life measurement tools, including the VAS, the McGill Pain Questionnaire, the 36-item Short-Form Quality of Life Health Survey (SF-36), and the EuroQol-5 Domain Quality of Life Questionnaire (EQ-5D). No a priori level of improvement on any of the measurement tools was set to determine efficacy. Pain etiologies included failed back surgery syndrome, poststroke pain, brachial plexus injury, cervical spinal cord injury, head injury, and pain of unknown origin, and distributions varied from whole body to isolated limbs. Of the 15 fully implanted patients, 11 subjects were included in the final analysis.

In this study, the investigators observed a statistically insignificant overall improvement in the VAS of $24.5 \%$, with a range of $-41 \%$ to $100 \%$. For 5 patients, average VAS scores dropped below 4 on a scale of $1-10$, indicating mild pain, and 1 patient reported freedom from pain at 17 months after surgery. Statistically significant improvements were observed in the Physical Functioning and Bodily Pain domains of the SF-36, as well as on the EQ-5D, which evaluates 5 health dimensions including mobility, self-care, usual activities, pain, and anxiety. No major adverse events were discussed in this series, and it is unclear whether any unexpected stimulation effects, other than those discussed above, were observed. The investigators concluded that dACC DBS is a viable option for the treatment of medically refractory chronic pain.

In interpreting the results of this study, several important considerations arise. The first is that the population treated in this study is heterogeneous; patients with a number of chronic pain syndromes, arising through several different injury mechanisms, were included in this group. It is possible that certain pain etiologies may be more responsive to dACC DBS than others. Likewise, differences in anatomy, arising naturally or as a result of physiological postinjury changes, may alter responsiveness to DBS treatment. Additional study may determine that individualized targeting improves outcomes or that certain imaging features are predictive of good outcomes. Finally, as discussed above, studies exploring the circuitry of pain perception have consistently identified the dorsal anterior cingulate as being involved in the "affective component" of pain. That is, activity of the dACC during painful stimululation has been associated with the negative emotional experience of pain rather than the nociceptive experience. Therefore, scales such as the VAS, which focus primarily on the nociceptive aspect of pain, may not adequately address changes in the perception of pain effected by this surgical intervention. It is possible that scales that aim to assess quality of life or the impact of pain on daily functioning may be more appropriate choices for adequate outcome assessment.

Interestingly, Parvizi and colleagues recently published a case study describing the subjective experience of the effects of electric brain stimulation of the dACC on 2 epilepsy patients. ${ }^{12}$ Stimulation was delivered via implanted intracranial electrodes that were used clinically to identify epileptogenic foci. Upon application of stimulation, the investigators noted stereotyped cognitive, emotional, and autonomic reactions that they characterized as demonstrating a "will to persevere." Patients described feeling a sense of foreboding that was accompanied by a belief that they would be able to overcome the obstacles facing them. The investigators used resting state fMRI to support the idea that this effect may result from activation of networks through the dACC that are involved in assigning salience. Although this study described the effects of acute stimulation rather than chronic stimulation as would occur with DBS, it corroborates a framework from which to understand how electrical modulation of the dACC might produce affective pain "relief." The findings concord with the notion that the component of pain targeted by this therapeutic intervention is not the sensorial experience itself but rather the perceived emotional "burden" or "bother."

\section{Additional Considerations}

The dorsal anterior cingulate has been implicated in a diverse range of cognitive, mood, and affective processes, raising concern about the potential for adverse effects related to chronic stimulation of the dACC. ${ }^{41,56,61,62,147}$ Little direct evidence of stimulation effects is available in the literature. Assessment and discussion of risk must draw on lessons extracted from the more robust cingulotomy and existing DBS literature.

A common criticism of the literature surrounding cingulotomy for refractory pain is that evaluation of the effects on patient mood, personality, and cognition has not been systematic. Negative effects on attention, executive function, and behavior have been noted in several studies, but few formal evaluations have been performed..$^{20,33}$ Cohen and colleagues attempted to address the question of the neuropsychiatric impact of bilateral cingulotomy prospectively in a cohort of 12 patients with nonmalignant chronic pain. At the 1-year postoperative evaluation, the investigators found decreased intention and spontaneous response production as well as mildly compromised executive function. Deficits were identified in performance of the Stroop interference task and the Adaptive Rate Continuous Performance Test Inconsistency Index, which the 
investigators classified as a task of sustained attention. ${ }^{32} \mathrm{~A}$ study by Yen and colleagues designed to assess neurocognitive effects of cingulotomy also noted a postcingulotomy deficit in performance on the Stroop task, although the effect was transient. ${ }^{161}$

In considering the lessons learned from cingulotomy in assessing the theoretical neuropsychiatric and cognitive risks of targeting the $\mathrm{dACC}$ for DBS, it is important to consider that the effects of DBS are likely the summation of modulating effects at both the neuronal and network levels. ${ }^{19,128,145,146,156,160}$ Stimulation is therefore hypothesized to impact not only the target and its immediately surrounding structures, but also neural networks that may have far-reaching branches. ${ }^{39,94,119}$ The extent of the neural activation associated with DBS was recently demonstrated by Riva-Posse and colleagues by applying DTI tractography and finite element models of electrical field propagation to create individualized maps of stimulation-induced activation in DBS patients. ${ }^{124}$ Other studies have looked at markers of cortical activity such as neurotransmitter levels, changes in neuronal morphology, or cerebral blood flow for evidence of alteration in the activity of neural circuitry as a result of chronic neurostimulation, with similar conclusions. $^{2}$

An additional factor to consider is the impact that chronic pain has on cognitive and emotional processing. ${ }^{78,110}$ The IASP published a clinical update on their website in 2007 , reviewing the data surrounding the impact of chronic pain on cognitive functioning. ${ }^{78}$ Two conclusions were drawn from their review of the literature: 1) chronic pain has a negative effect on cognition, and 2) cognitive impairment has the potential to impair patient communication of pain and reduce the effectiveness of cognitive therapies. The deficits noted most commonly in the literature involved attention, memory, verbal fluency, processing speed, and mental flexibility. The authors also pointed out the fact that analysis of the effect of chronic pain on cognition is confounded by commonly used medical treatments, such as opioid painkillers, which may independently impact cognitive functioning. Therefore, it is possible that DBS of the ACC may improve cognitive functioning by a 2-fold process, that is, by both alleviating the patient's pain and by reducing reliance on obtunding medications.

\section{Conclusions}

Chronic neuropathic pain is one of the most common and costly health complaints in the world today. It has the potential to interfere with all aspects of a patient's life, resulting in missed days of work, withdrawal from the workforce, greater health resource utilization, and strained interpersonal relationships. According to the American Academy of Pain Medicine, more than 1.5 billion people worldwide currently suffer from chronic pain, and 3\%$4.5 \%$ of the worldwide population qualifies as having neuropathic pain, which often does not respond to available treatments. ${ }^{66}$ Combating chronic pain is currently a national health initiative here in the United States.

The role of DBS in the treatment of chronic refractory neuropathic pain is currently unknown. ${ }^{36}$ Advancements in neuroimaging and neuronal recording techniques over the past decade have refined our understanding of neural circuitry and led to the identification of new targets for therapy. The dACC has long been an area of interest for the treatment of refractory pain. Recent pilot studies of DBS targeting the ACC for the treatment of chronic neuropathic pain have shown encouraging results in the alleviation of what is often an untreatable and disabling condition.

\section{References}

1. Adams JE, Hosobuchi Y, Fields HL: Stimulation of internal capsule for relief of chronic pain. J Neurosurg 41:740-744, 1974

2. Anderson RJ, Frye MA, Abulseoud OA, Lee KH, McGillivray JA, Berk M, et al: Deep brain stimulation for treatment-resistant depression: efficacy, safety and mechanisms of action. Neurosci Biobehav Rev 36:1920-1933, 2012

3. Apkarian AV: The brain in chronic pain: clinical implications. Pain Manag 1:577-586, 2011

4. Apkarian AV: Pain perception in relation to emotional learning. Curr Opin Neurobiol 18:464-468, 2008

5. Apkarian AV, Baliki MN, Farmer MA: Predicting transition to chronic pain. Curr Opin Neurol 26:360-367, 2013

6. Apkarian AV, Baliki MN, Geha PY: Towards a theory of chronic pain. Prog Neurobiol 87:81-97, 2009

7. Apkarian AV, Neugebauer V, Koob G, Edwards S, Levine JD, Ferrari L, et al: Neural mechanisms of pain and alcohol dependence. Pharmacol Biochem Behav 112:34-41, 2013

8. Assaf Y, Pasternak O: Diffusion tensor imaging (DTI)based white matter mapping in brain research: a review. $\mathbf{J}$ Mol Neurosci 34:51-61, 2008

9. Ballantine HT Jr, Cassidy WL, Flanagan NB, Marino R Jr: Stereotaxic anterior cingulotomy for neuropsychiatric illness and intractable pain. J Neurosurg 26:488-495, 1967

10. Bantick SJ, Wise RG, Ploghaus A, Clare S, Smith SM, Tracey I: Imaging how attention modulates pain in humans using functional MRI. Brain 125:310-319, 2002

11. Bechara A, Damasio AR, Damasio H, Anderson SW: Insensitivity to future consequences following damage to human prefrontal cortex. Cognition 50:7-15, 1994

12. Bernhardt BC, Singer T: The neural basis of empathy. Annu Rev Neurosci 35:1-23, 2012

13. Bissonette GB, Powell EM, Roesch MR: Neural structures underlying set-shifting: roles of medial prefrontal cortex and anterior cingulate cortex. Behav Brain Res 250:91-101, 2013

14. Bittar RG, Kar-Purkayastha I, Owen SL, Bear RE, Green A, Wang S, et al: Deep brain stimulation for pain relief: a meta-analysis. J Clin Neurosci 12:515-519, 2005

15. Blom SM, Pfister JP, Santello M, Senn W, Nevian T: Nerve injury-induced neuropathic pain causes disinhibition of the anterior cingulate cortex. J Neurosci 34:5754-5764, 2014

16. Boccard SG, Pereira EA, Moir L, Aziz TZ, Green AL: Long-term outcomes of deep brain stimulation for neuropathic pain. Neurosurgery 72:221-231, 2013

17. Boccard SG, Pereira EA, Moir L, Van Hartevelt TJ, Kringelbach ML, FitzGerald JJ, et al: Deep brain stimulation of the anterior cingulate cortex: targeting the affective component of chronic pain. Neuroreport 25:83-88, 2014

18. Boivie J: Central post stroke pain, in Cervero F, Jensen TS (eds): Handbook of Clinical Neurology: Pain. Amsterdam: Elsevier, 2006, Vol 81, pp 715-730

19. Bourne SK, Eckhardt CA, Sheth SA, Eskandar EN: Mechanisms of deep brain stimulation for obsessive compulsive disorder: effects upon cells and circuits. Front Integr Neurosci 6:29, 2012

20. Brotis AG, Kapsalaki EZ, Paterakis K, Smith JR, Fountas 
KN: Historic evolution of open cingulectomy and stereotactic cingulotomy in the management of medically intractable psychiatric disorders, pain and drug addiction. Stereotact Funct Neurosurg 87:271-291, 2009

21. Burchiel KJ: Neurostimulation for chronic noncancer pain. J Neurosurg 105: 174, 2006

22. Bush G, Luu P, Posner MI: Cognitive and emotional influences in anterior cingulate cortex. Trends Cogn Sci 4:215222,2000

23. Casey KL, Lorenz J, Minoshima S: Insights into the pathophysiology of neuropathic pain through functional brain imaging. Exp Neurol 184 (Suppl 1):S80-S88, 2003

24. Casey KL, Tran TD: Cortical mechanisms mediating acute and chronic pain in humans, in Handbook of Clinical Neurology: Pain. Amsterdam: Elsevier, 2006, Vol 81, pp 159-178

25. Cetas JS, Saedi T, Burchiel KJ: Destructive procedures for the treatment of nonmalignant pain: a structured literature review. J Neurosurg 109:389-404, 2008

26. Chen T, Koga K, Descalzi G, Qiu S, Wang J, Zhang LS, et al: Postsynaptic potentiation of corticospinal projecting neurons in the anterior cingulate cortex after nerve injury. Mol Pain 10:33, 2014

27. Chen T, Wang W, Dong YL, Zhang MM, Wang J, Koga K, et al: Postsynaptic insertion of AMPA receptor onto cortical pyramidal neurons in the anterior cingulate cortex after peripheral nerve injury. Mol Brain 7:76, 2014

28. Coffey RJ: Deep brain stimulation devices: a brief technical history and review. Artif Organs 33:208-220, 2009

29. Coffey RJ: Deep brain stimulation for chronic pain: results of two multicenter trials and a structured review. Pain Med 2:183-192, 2001

30. Coffey RJ, Lozano AM: Neurostimulation for chronic noncancer pain: an evaluation of the clinical evidence and recommendations for future trial designs. J Neurosurg 105: 175-189, 2006

31. Cohen MX, Heller AS, Ranganath C: Functional connectivity with anterior cingulate and orbitofrontal cortices during decision-making. Brain Res Cogn Brain Res 23:61-70, 2005

32. Cohen RA, Kaplan RF, Moser DJ, Jenkins MA, Wilkinson $\mathrm{H}$ : Impairments of attention after cingulotomy. Neurology 53:819-824, 1999

33. Cohen RA, Paul R, Zawacki TM, Moser DJ, Sweet L, Wilkinson H: Emotional and personality changes following cingulotomy. Emotion 1:38-50, 2001

34. Cooperrider J, Furmaga H, Plow E, Park HJ, Chen Z, Kidd $\mathrm{G}$, et al: Chronic deep cerebellar stimulation promotes longterm potentiation, microstructural plasticity, and reorganization of perilesional cortical representation in a rodent model. J Neurosci 34:9040-9050, 2014

35. Craig AD, Reiman EM, Evans A, Bushnell MC: Functional imaging of an illusion of pain. Nature 384:258-260, 1996

36. Cruccu G, Aziz TZ, Garcia-Larrea L, Hansson P, Jensen TS, Lefaucheur JP, et al: EFNS guidelines on neurostimulation therapy for neuropathic pain. Eur J Neurol 14:952970, 2007

37. Davis KD: Neurophysiological and anatomical considerations in functional imaging of pain. Pain 105:1-3, 2003

38. Davis KD, Moayedi M: Central mechanisms of pain revealed through functional and structural MRI. J Neuroimmune Pharmacol 8:518-534, 2013

39. Davis KD, Taub E, Duffner F, Lozano AM, Tasker RR, Houle $S$, et al: Activation of the anterior cingulate cortex by thalamic stimulation in patients with chronic pain: a positron emission tomography study. J Neurosurg 92:64-69, 2000

40. Davis KD, Taylor KS, Anastakis DJ: Nerve injury triggers changes in the brain. Neuroscientist 17:407-422, 2011
41. Davis KD, Taylor KS, Hutchison WD, Dostrovsky JO, McAndrews MP, Richter EO, et al: Human anterior cingulate cortex neurons encode cognitive and emotional demands. J Neurosci 25:8402-8406, 2005

42. Davis KD, Taylor SJ, Crawley AP, Wood ML, Mikulis DJ: Functional MRI of pain- and attention-related activations in the human cingulate cortex. J Neurophysiol 77:3370-3380, 1997

43. Descalzi G, Kim S, Zhuo M: Presynaptic and postsynaptic cortical mechanisms of chronic pain. Mol Neurobiol 40:253-259, 2009

44. Devinsky O, Morrell MJ, Vogt BA: Contributions of anterior cingulate cortex to behaviour. Brain 118:279-306, 1995

45. Devor M, De Koninck Y, Sommer CL: Underlying mechanisms of neuropathic pain, in Raja SN, Sommer CL (eds): Pain 2014: Refresher Courses, 15th World Congress on Pain. Washington, DC: IASP Press, 2014, pp 187-198

46. Duncan GH, Bushnell MC, Marchand S: Deep brain stimulation: a review of basic research and clinical studies. Pain 45:49-59, 1991

47. Egli M, Koob GF, Edwards S: Alcohol dependence as a chronic pain disorder. Neurosci Biobehav Rev 36:21792192, 2012

48. Elliott AM, Smith BH, Penny KI, Smith WC, Chambers WA: The epidemiology of chronic pain in the community. Lancet 354: 1248-1252, 1999

49. Engen HG, Singer T: Empathy circuits. Curr Opin Neurobiol 23:275-282, 2013

50. Etkin A, Egner T, Kalisch R: Emotional processing in anterior cingulate and medial prefrontal cortex. Trends Cogn Sci 15:85-93, 2011

51. Foltz EL, White LE Jr: Pain "relief" by frontal cingulumotomy. J Neurosurg 19:89-100, 1962

52. Fossati P: Neural correlates of emotion processing: from emotional to social brain. Eur Neuropsychopharmacol 22 (Suppl 3):S487-S491, 2012

53. Garcia-Larrea L: The pathophysiology of neuropathic pain: critical review of models and mechanisms, in Raja SN, Sommer CL (eds): Pain 2014: Refresher Courses, 15th World Congress on Pain. Washington, DC: IASP Press, 2014, pp 453-475

54. Gasquoine PG: Localization of function in anterior cingulate cortex: from psychosurgery to functional neuroimaging. Neurosci Biobehav Rev 37:340-348, 2013

55. Gläscher J, Adolphs R, Damasio H, Bechara A, Rudrauf D, Calamia M, et al: Lesion mapping of cognitive control and value-based decision making in the prefrontal cortex. Proc Natl Acad Sci U S A 109: 14681-14686, 2012

56. Gray AM, Pounds-Cornish E, Eccles FJ, Aziz TZ, Green AL, Scott RB: Deep brain stimulation as a treatment for neuropathic pain: a longitudinal study addressing neuropsychological outcomes. J Pain 15:283-292, 2014

57. Green AL, Wang S, Owen SL, Xie K, Bittar RG, Stein JF, et al: Stimulating the human midbrain to reveal the link between pain and blood pressure. Pain 124:349-359, 2006

58. Green AL, Wang S, Stein JF, Pereira EA, Kringelbach ML, Liu X, et al: Neural signatures in patients with neuropathic pain. Neurology 72:569-571, 2009

59. Gureje O, Von Korff M, Simon GE, Gater R: Persistent pain and well-being: a World Health Organization Study in Primary Care. JAMA 280: 147-151, 1998

60. Gybels J, Kupers R: Deep brain stimulation in the treatment of chronic pain in man: where and why? Neurophysiol Clin 20:389-398, 1990

61. Halpern CH, Rick JH, Danish SF, Grossman M, Baltuch $\mathrm{GH}$ : Cognition following bilateral deep brain stimulation surgery of the subthalamic nucleus for Parkinson's disease. Int J Geriatr Psychiatry 24:443-451, 2009

62. Hamani C, Schwalb JM, Rezai AR, Dostrovsky JO, Davis 
KD, Lozano AM: Deep brain stimulation for chronic neuropathic pain: long-term outcome and the incidence of insertional effect. Pain 125: 188-196, 2006

63. Henry DE, Chiodo AE, Yang W: Central nervous system reorganization in a variety of chronic pain states: a review. PM R 3:1116-1125, 2011

64. Hosobuchi Y: Subcortical electrical stimulation for control of intractable pain in humans. Report of 122 cases (19701984). J Neurosurg 64:543-553, 1986

65. Hutchison WD, Davis KD, Lozano AM, Tasker RR, Dostrovsky JO: Pain-related neurons in the human cingulate cortex. Nat Neurosci 2:403-405, 1999

66. Institute of Medicine: Relieving Pain in America. A Blueprint for Transforming Prevention, Care, Education and Research. Washington, DC: National Academy of Sciences, 2011

67. Inui K, Tran TD, Qiu Y, Wang X, Hoshiyama M, Kakigi R: A comparative magnetoencephalographic study of cortical activations evoked by noxious and innocuous somatosensory stimulations. Neuroscience 120:235-248, 2003

68. Iwata K, Kamo H, Ogawa A, Tsuboi Y, Noma N, Mitsuhashi Y, et al: Anterior cingulate cortical neuronal activity during perception of noxious thermal stimuli in monkeys. J Neurophysiol 94:1980-1991, 2005

69. Jahn A, Nee DE, Alexander WH, Brown JW: Distinct regions of anterior cingulate cortex signal prediction and outcome evaluation. Neuroimage 95:80-89, 2014

70. Jensen TS, Baron R, Haanpää M, Kalso E, Loeser JD, Rice AS, et al: A new definition of neuropathic pain. Pain 152: 2204-2205, 2011

71. Kakigi R, Watanabe S, Yamasaki H: Pain-related somatosensory evoked potentials. J Clin Neurophysiol 17:295308,2000

72. Kennerley SW, Walton ME, Behrens TE, Buckley MJ, Rushworth MF: Optimal decision making and the anterior cingulate cortex. Nat Neurosci 9:940-947, 2006

73. King T, Qu C, Okun A, Melemedjian OK, Mandell EK, Maskaykina IY, et al: Contribution of PKM $\zeta$-dependent and independent amplification to components of experimental neuropathic pain. Pain 153:1263-1273, 2012

74. Klit H, Finnerup NB, Jensen TS: Central post-stroke pain: clinical characteristics, pathophysiology, and management. Lancet Neurol 8:857-868, 2009

75. Koyama T, Kato K, Mikami A: During pain-avoidance neurons activated in the macaque anterior cingulate and caudate. Neurosci Lett 283:17-20, 2000

76. Koyama T, Kato K, Tanaka YZ, Mikami A: Anterior cingulate activity during pain-avoidance and reward tasks in monkeys. Neurosci Res 39:421-430, 2001

77. Koyama T, Tanaka YZ, Mikami A: Nociceptive neurons in the macaque anterior cingulate activate during anticipation of pain. Neuroreport 9:2663-2667, 1998

78. Kreitler S, Niv D: Cognitive impairment in chronic pain. Pain Clinical Updates 15:1-4, 2007

79. Kringelbach ML, Aziz TZ: Deep brain stimulation: avoiding the errors of psychosurgery. JAMA 301:1705-1707, 2009

80. Kringelbach ML, Jenkinson N, Green AL, Owen SL, Hansen PC, Cornelissen PL, et al: Deep brain stimulation for chronic pain investigated with magnetoencephalography. Neuroreport 18:223-228, 2007

81. Kumar K, Toth C, Nath RK: Deep brain stimulation for intractable pain: a 15-year experience. Neurosurgery 40: 736-747, 1997

82. Kupers R, Kehlet H: Brain imaging of clinical pain states: a critical review and strategies for future studies. Lancet Neurol 5:1033-1044, 2006

83. LaGraize SC, Labuda CJ, Rutledge MA, Jackson RL, Fuchs PN: Differential effect of anterior cingulate cortex lesion on mechanical hypersensitivity and escape/avoidance behav- ior in an animal model of neuropathic pain. Exp Neurol 188: 139-148, 2004

84. Lamm C, Decety J, Singer T: Meta-analytic evidence for common and distinct neural networks associated with directly experienced pain and empathy for pain. Neuroimage 54:2492-2502, 2011

85. Lenz FA, Rios M, Zirh A, Chau D, Krauss G, Lesser RP: Painful stimuli evoke potentials recorded over the human anterior cingulate gyrus. J Neurophysiol 79:2231-2234, 1998

86. Lewin W, Whitty CW: Effects of anterior cingulate stimulation in conscious human subjects. J Neurophysiol 23:445447, 1960

87. Li W, Wang P, Li H: Upregulation of glutamatergic transmission in anterior cingulate cortex in the diabetic rats with neuropathic pain. Neurosci Lett 568:29-34, 2014

88. Li XY, Ko HG, Chen T, Collingridge GL, Kaang BK, Zhuo M: Erasing injury-related cortical synaptic potentiation as a new treatment for chronic pain. J Mol Med (Berl) 89:847855,2011

89. Li XY, Ko HG, Chen T, Descalzi G, Koga K, Wang H, et al: Alleviating neuropathic pain hypersensitivity by inhibiting PKMzeta in the anterior cingulate cortex. Science 330:1400-1404, 2010

90. Lindquist KA, Barrett LF: A functional architecture of the human brain: emerging insights from the science of emotion. Trends Cogn Sci 16:533-540, 2012

91. Lorenz J, Minoshima S, Casey KL: Keeping pain out of mind: the role of the dorsolateral prefrontal cortex in pain modulation. Brain 126: 1079-1091, 2003

92. 129. Lozano AM, Giacobbe P, Hamani C, Rizvi SJ, Kolivakis TT, Debonnel G, et al: A multicenter pilot study of subcallosal cingulate area deep brain stimulation for treatment-resistant depression. J Neurosurg 116:315-322, 2012

93. Lui F, Duzzi D, Corradini M, Serafini M, Baraldi P, Porro CA: Touch or pain? Spatio-temporal patterns of cortical fMRI activity following brief mechanical stimuli. Pain 138: 362-374, 2008

94. Lujan JL, Chaturvedi A, Choi KS, Holtzheimer PE, Gross RE, Mayberg HS, et al: Tractography-activation models applied to subcallosal cingulate deep brain stimulation. Brain Stimulat 6:737-739, 2013

95. May A: Chronic pain may change the structure of the brain. Pain 137:7-15, 2008

96. Melzack R: Evolution of the neuromatrix theory of pain. Pain Pract 5:85-94, 2005

97. Melzack R: Gate control theory: on the evolution of pain concepts. Pain Forum 5:128-138, 1996

98. Melzack R: The McGill pain questionnaire: from description to measurement. Anesthesiology 103:199-202, 2005

99. Melzack R: Pain - an overview. Acta Anaesthesiol Scand 43:880-884, 1999

100. Melzack R: Pain and the neuromatrix in the brain. J Dent Educ 65:1378-1382, 2001

101. Melzack R, Coderre TJ, Katz J, Vaccarino AL: Central neuroplasticity and pathological pain. Ann N Y Acad Sci 933:157-174, 2001

102. Melzack R, Wall PD: Pain mechanisms: a new theory. Science 150:971-979, 1965

103. Mohseni HR, Smith PP, Parsons CE, Young KS, Hyam JA, Stein A, et al: MEG can map short and long-term changes in brain activity following deep brain stimulation for chronic pain. PLoS ONE 7:e37993, 2012

104. Moisset X, Bouhassira D: Brain imaging of neuropathic pain. Neuroimage 37 (Suppl 1):S80-S88, 2007

105. Mordasini L, Weisstanner C, Rummel C, Thalmann GN, Verma RK, Wiest R, et al: Chronic pelvic pain syndrome in men is associated with reduction of relative gray matter 
volume in the anterior cingulate cortex compared to healthy controls. J Urol 188:2233-2237, 2012

106. Nandi D, Yianni J, Humphreys J, Wang S, O'Sullivan V, Shepstone B, et al: Phantom limb pain relieved with different modalities of central nervous system stimulation: a clinical and functional imaging case report of two patients. Neuromodulation 7:176-183, 2004

107. Narita M, Kuzumaki N, Narita M, Kaneko C, Hareyama N, Miyatake M, et al: Chronic pain-induced emotional dysfunction is associated with astrogliosis due to cortical $\delta$-opioid receptor dysfunction. J Neurochem 97:1369-1378, 2006

108. Ness TJ, San Pedro EC, Richards JS, Kezar L, Liu HG, Mountz JM: A case of spinal cord injury-related pain with baseline rCBF brain SPECT imaging and beneficial response to gabapentin. Pain 78:139-143, 1998

109. Niikura K, Furuya M, Narita M, Torigoe K, Kobayashi Y, Takemura Y, et al: Enhancement of glutamatergic transmission in the cingulate cortex in response to mild noxious stimuli under a neuropathic pain-like state. Synapse 65:424-432, 2011

110. Noll-Hussong M, Otti A, Wohlschlaeger AM, Zimmer C, Henningsen P, Lahmann C, et al: Neural correlates of deficits in pain-related affective meaning construction in patients with chronic pain disorder. Psychosom Med 75:124-136, 2013

111. Osaka N, Osaka M, Morishita M, Kondo H, Fukuyama $\mathrm{H}$ : A word expressing affective pain activates the anterior cingulate cortex in the human brain: an fMRI study. Behav Brain Res 153:123-127, 2004

112. Parvizi J, Rangarajan V, Shirer WR, Desai N, Greicius MD: The will to persevere induced by electrical stimulation of the human cingulate gyrus. Neuron 80:1359-1367, 2013

113. Pereira EAC, Aziz TZ: Neuropathic pain and deep brain stimulation. Neurotherapeutics 11:496-507, 2014

114. Pereira EAC, Boccard SG, Linhares P, Chamadoira C, Rosas MJ, Abreu P, et al: Thalamic deep brain stimulation for neuropathic pain after amputation or brachial plexus avulsion. Neurosurg Focus 35(3):E7, 2013

115. Pereira EAC, Green AL, Aziz TZ: Deep brain stimulation for pain, in Lozano AM, Hallett M (eds): Handbook of Clinical Neurology: Brain Stimulation. Amsterdam: Elsevier, 2013, Vol 116, pp 277-294

116. Pereira EAC, Green AL, Bradley KM, Soper N, Moir L, Stein JF, et al: Regional cerebral perfusion differences between periventricular grey, thalamic and dual target deep brain stimulation for chronic neuropathic pain. Stereotact Funct Neurosurg 85:175-183, 2007

117. Peyron R, Laurent B, García-Larrea L: Functional imaging of brain responses to pain. A review and meta-analysis (2000). Neurophysiol Clin 30:263-288, 2000

118. Peyron R, Schneider F, Faillenot I, Convers P, Barral FG, Garcia-Larrea L, et al: An fMRI study of cortical representation of mechanical allodynia in patients with neuropathic pain. Neurology 63:1838-1846, 2004

119. Piasecki SD, Jefferson JW: Psychiatric complications of deep brain stimulation for Parkinson's disease. J Clin Psychiatry 65:845-849, 2004

120. Ploner M, Gross J, Timmermann L, Schnitzler A: Cortical representation of first and second pain sensation in humans. Proc Natl Acad Sci U S A 99: 12444-12448, 2002

121. Qu C, King T, Okun A, Lai J, Fields HL, Porreca F: Lesion of the rostral anterior cingulate cortex eliminates the aversiveness of spontaneous neuropathic pain following partial or complete axotomy. Pain 152:1641-1648, 2011

122. Rainville P, Duncan GH, Price DD, Carrier B, Bushnell MC: Pain affect encoded in human anterior cingulate but not somatosensory cortex. Science 277:968-971, 1997

123. Ray NJ, Jenkinson N, Kringelbach ML, Hansen PC, Pereira
EA, Brittain JS, et al: Abnormal thalamocortical dynamics may be altered by deep brain stimulation: using magnetoencephalography to study phantom limb pain. J Clin Neurosci 16:32-36, 2009

124. Riva-Posse P, Choi KS, Holtzheimer PE, McIntyre CC, Gross RE, Chaturvedi A, et al: Defining critical white matter pathways mediating successful subcallosal cingulate deep brain stimulation for treatment-resistant depression. Biol Psychiatry 76:963-969, 2014

125. Rodriguez-Raecke R, Niemeier A, Ihle K, Ruether W, May A: Structural brain changes in chronic pain reflect probably neither damage nor atrophy. PLoS ONE 8:e54475, 2013

126. Rolls ET: Emotion and decision-making explained: response to commentators. Cortex 62:203-210, 2015

127. Rolls ET: Limbic systems for emotion and for memory, but no single limbic system. Cortex 62:119-157, 2015

128. Saab CY: Pain-related changes in the brain: diagnostic and therapeutic potentials. Trends Neurosci 35:629-637, 2012

129. Schlaepfer T, Bewenick B: Deep brain stimulation for major depression, in Lozano AM, Hallett M (eds): Handbook of Clinical Neurology: Brain Simulation. Amsterdam: Elsevier, 2013, Vol 116, pp 235-243

130. Schnitzler A, Ploner M: Neurophysiology and functional neuroanatomy of pain perception. J Clin Neurophysiol 17:592-603, 2000

131. Seminowicz DA, Davis KD: Pain enhances functional connectivity of a brain network evoked by performance of a cognitive task. J Neurophysiol 97:3651-3659, 2007

132. Shackman AJ, Salomons TV, Slagter HA, Fox AS, Winter JJ, Davidson RJ: The integration of negative affect, pain and cognitive control in the cingulate cortex. Nat Rev Neurosci 12:154-167, 2011

133. Sharif-Naeini R, Basbaum AI: Targeting pain where it resides ... in the brain. Sci Transl Med 3:65ps 1, 2011

134. Sheth SA, Mian MK, Patel SR, Asaad WF, Williams ZM, Dougherty DD, et al: Human dorsal anterior cingulate cortex neurons mediate ongoing behavioural adaptation. Nature 488:218-221, 2012

135. Sheth SA, Neal J, Tangherlini F, Mian MK, Gentil A, Cosgrove GR, et al: Limbic system surgery for treatmentrefractory obsessive-compulsive disorder: a prospective long-term follow-up of 64 patients. J Neurosurg 118:491497, 2013

136. Shyu BC, Vogt BA: Short-term synaptic plasticity in the nociceptive thalamic-anterior cingulate pathway. Mol Pain 5:51, 2009

137. Siddall PJ, Stanwell P, Woodhouse A, Somorjai RL, Dolenko B, Nikulin A, et al: Magnetic resonance spectroscopy detects biochemical changes in the brain associated with chronic low back pain: a preliminary report. Anesth Analg 102:1164-1168, 2006

138. Singer T, Lamm C: The social neuroscience of empathy. Ann N Y Acad Sci 1156:81-96, 2009

139. Singer T, Seymour B, O'Doherty J, Kaube H, Dolan RJ, Frith CD: Empathy for pain involves the affective but not sensory components of pain. Science 303:1157-1162, 2004

140. Spangler WJ, Cosgrove GR, Ballantine HT Jr, Cassem EH, Rauch SL, Nierenberg A, et al: Magnetic resonance imageguided stereotactic cingulotomy for intractable psychiatric disease. Neurosurgery 38:1071-1078, 1996

141. Spooner J, Yu H, Kao C, Sillay K, Konrad P: Neuromodulation of the cingulum for neuropathic pain after spinal cord injury. Case report. J Neurosurg 107:169-172, 2007

142. Stanwell P, Siddall P, Keshava N, Cocuzzo D, Ramadan $\mathrm{S}$, Lin A, et al: Neuro magnetic resonance spectroscopy using wavelet decomposition and statistical testing identifies biochemical changes in people with spinal cord injury and pain. Neuroimage 53:544-552, 2010 
143. Stewart WF, Ricci JA, Chee E, Morganstein D: Lost productive work time costs from health conditions in the United States: results from the American Productivity Audit. J Occup Environ Med 45:1234-1246, 2003

144. Tachibana K, Kato R, Tsuruga K, Takita K, Hashimoto T, Morimoto Y: Altered synaptic transmission in rat anterior cingulate cortex following peripheral nerve injury. Brain Res 1238:53-58, 2008

145. Taghva AS, Malone DA, Rezai AR: Deep brain stimulation for treatment-resistant depression. World Neurosurg 80:S27.e17-S27.e24, 2013

146. Takeshita S, Kurisu K, Trop L, Arita K, Akimitsu T, Verhoeff NPL: Effect of subthalamic stimulation on mood state in Parkinson's disease: evaluation of previous facts and problems. Neurosurg Rev 28:179-187, 2005

147. Todd RM, Cunningham WA, Anderson AK, Thompson E: Affect-biased attention as emotion regulation. Trends Cogn Sci 16:365-372, 2012

148. Tseng MT, Chiang MC, Chao CC, Tseng WYI, Hsieh ST: fMRI evidence of degeneration-induced neuropathic pain in diabetes: enhanced limbic and striatal activations. Hum Brain Mapp 34:2733-2746, 2013

149. Tzabazis A, Aparici CM, Rowbotham MC, Schneider MB, Etkin A, Yeomans DC: Shaped magnetic field pulses by multi-coil repetitive transcranial magnetic stimulation (rTMS) differentially modulate anterior cingulate cortex responses and pain in volunteers and fibromyalgia patients. Mol Pain 9:33, 2013

150. van den Heuvel MP, Hulshoff Pol HE: Exploring the brain network: a review on resting-state fMRI functional connectivity. Eur Neuropsychopharmacol 20:519-534, 2010

151. Viswanathan A, Harsh V, Pereira EA, Aziz TZ: Cingulotomy for medically refractory cancer pain. Neurosurg Focus 35(3):E1, 2013

152. Vogt BA: Pain and emotion interactions in subregions of the cingulate gyrus. Nat Rev Neurosci 6:533-544, 2005

153. Vogt BA: Submodalities of emotion in the context of cingulate subregions. Cortex 59:197-202, 2014

154. Wallis JD, Kennerley SW: Contrasting reward signals in the orbitofrontal cortex and anterior cingulate cortex. Ann N Y Acad Sci 1239:33-42, 2011

155. Wang H, Xu H, Wu LJ, Kim SS, Chen T, Koga K, et al: Identification of an adenylyl cyclase inhibitor for treating neuropathic and inflammatory pain. Sci Transl Med 3:65ra3, 2011

156. Weaver FM, Follett K, Stern M, Hur K, Harris C, Marks WJJ Jr, et al: Bilateral deep brain stimulation vs best medical therapy for patients with advanced Parkinson disease: a randomized controlled trial. JAMA 301:63-73, 2009
157. Weible AP: Remembering to attend: the anterior cingulate cortex and remote memory. Behav Brain Res 245:63-75, 2013

158. Whalen PJ, Bush G, McNally RJ, Wilhelm S, McInerney SC, Jenike MA, et al: The emotional counting Stroop paradigm: a functional magnetic resonance imaging probe of the anterior cingulate affective division. Biol Psychiatry 44:1219-1228, 1998

159. Wilkinson HA, Davidson KM, Davidson RI: Bilateral anterior cingulotomy for chronic noncancer pain. Neurosurgery 45:1129-1136, 1999

160. Witt K, Daniels C, Reiff J, Krack P, Volkmann J, Pinsker $\mathrm{MO}$, et al: Neuropsychological and psychiatric changes after deep brain stimulation for Parkinson's disease: a randomised, multicentre study. Lancet Neurol 7:605-614, 2008

161. Yen CP, Kuan CY, Sheehan J, Kung SS, Wang CC, Liu $\mathrm{CK}$, et al: Impact of bilateral anterior cingulotomy on neurocognitive function in patients with intractable pain. J Clin Neurosci 16:214-219, 2009

162. Yen CP, Kung SS, Su YF, Lin WC, Howng SL, Kwan AL: Stereotactic bilateral anterior cingulotomy for intractable pain. J Clin Neurosci 12:886-890, 2005

163. Zhang L, Zhang Y, Zhao ZQ: Anterior cingulate cortex contributes to the descending facilitatory modulation of pain via dorsal reticular nucleus. Eur J Neurosci 22:1141-1148, 2005

164. Zhuo M: Cortical excitation and chronic pain. Trends Neurosci 31:199-207, 2008

165. Zhuo M: Long-term potentiation in the anterior cingulate cortex and chronic pain. Philos Trans R Soc Lond B Biol Sci 369:20130146, 2014

166. Zhuo M: Molecular mechanisms of pain in the anterior cingulate cortex. J Neurosci Res 84:927-933, 2006

167. Zhuo M: A synaptic model for pain: long-term potentiation in the anterior cingulate cortex. Mol Cells 23:259-271, 2007

\section{Author Contributions}

Conception and design: Russo. Acquisition of data: Russo. Analysis and interpretation of data: Russo. Drafting the article: Russo. Critically revising the article: Sheth. Reviewed submitted version of manuscript: Sheth. Approved the final version of the manuscript on behalf of both authors: Russo.

\section{Correspondence}

Jennifer F. Russo, 3810 Greystone Ave., \#504, Bronx, NY 10463. email: jfr2120@cumc.columbia.edu. 